\title{
ANALYSIS OF THE TYRE LOADS OF THE TRUCK TATRA 815 IN INTERACTION WITH THE GROUND
}

\author{
Veronika VALAŠKOVÁ ${ }^{1, *}$, Jozef VLČEK ${ }^{2}$ \\ ${ }^{1}$ Department of Structural Mechanics and Applied Mathematics, Faculty of Civil Engineering, \\ University of Žilina, Univerzitná 8215/1, 01026 Žilina, Slovakia. \\ 2 Department of Geotechnics, Faculty of Civil Engineering, University of Žilina, Univerzitná 8215/1, \\ 01026 Žilina, Slovakia. \\ corresponding author: veronika.valaskova@fstav.uniza.sk.
}

\begin{abstract}
Interaction between moving vehicle and ground represents the actual problem. Traffic seismicity affects the environment and causes worsening of its parameters. Several approaches have been developed to solve the phenomena of the vehicle-ground interaction. This problem needs to be analysed as a complex system when particular elements interact together. The interaction results in unique magnitudes of the contact forces. This paper presents the results of the analysis of vehicle-ground interaction. Calculations have been made in software ADINA using Finite Element Method. Dynamic characteristics of the vehicle have been determined according to the lorry Tatra 815 . Contact forces of the tyres have been applied as point and distributed load respectivelv.
\end{abstract}

\section{Keywords:}

Contact forces;

Finite Element Method;

Vehicle-ground interaction; Lorry T-815.

\section{Introduction}

Pavements are structures that are exposed to direct dynamic effects of the moving load. Unevenness of the pavement surface is the main source of kinematic excitation for the vehicle. They have significant influence on the magnitude of the contact forces between the pavement surface and the vehicle tyres. The actual load amplitude is variable of time and frequency domain. There are two basic approaches to obtain the required data - computational or experimental methods. The reliability of transport structures loaded by the heavy traffic needs a detailed analysis using vehicle-ground interaction computational model to describe the response of the ground to the vehicle loading $[1,2]$.

There are many possibilities how to create the computational model of the pavement and the vehicle. Two interaction models of $2 \mathrm{D}$ half-part model of the vehicle Tatra 815 and the ground were created and results of the comparison of outputs of these models are presented in this paper. In the first numerical simulation (S1), the contact load is modelled as a point load representing tyre contact forces. In the second numerical simulation (S2), contact load is simulated as a uniform distributed load over the tyre contact area. The theoretical solution is based on the Finite Element Method (FEM). FEM methods have been more widely used since computer calculations became part of the modelling tools. In this case, simulations S1 and S2 are non-stationary dynamic actions and they are described by the following differential equation:

$$
[\mathbf{M}] \cdot\{\ddot{u}(t)\}+[\mathbf{C}] \cdot\{\dot{u}(t)\}+[\mathbf{K}] \cdot\{u(t)\}=\{F(t)\},
$$

where $[\mathbf{M}],[\mathbf{C}]$ and $[\mathbf{K}]$ are mass, damping and stiffness matrices describing the spatial properties of the vehicle and pavement interaction.

\section{Numerical model of vehicle}

Several computing systems are available for the FEM dynamic analysis of the presented problem. Models for simulation 1 (S1) and simulation 2 (S2) have been created in ADINA software. Particular elements of corresponding models S1 and S2 were assumed modular. Two main parts of 
the system lorry-ground have been a lorry with subsequent simplification to the dynamic subsystems and a half space representing the ground under the pavement surface. For the simulations, the halfpart model of the lorry Tatra 815 has been selected (Fig. 1). A discrete model of the vehicle with finite degrees of freedom simplifies the mathematical solution of the problem. This assumption transforms partial differential equations to the ordinary differential equations [3].
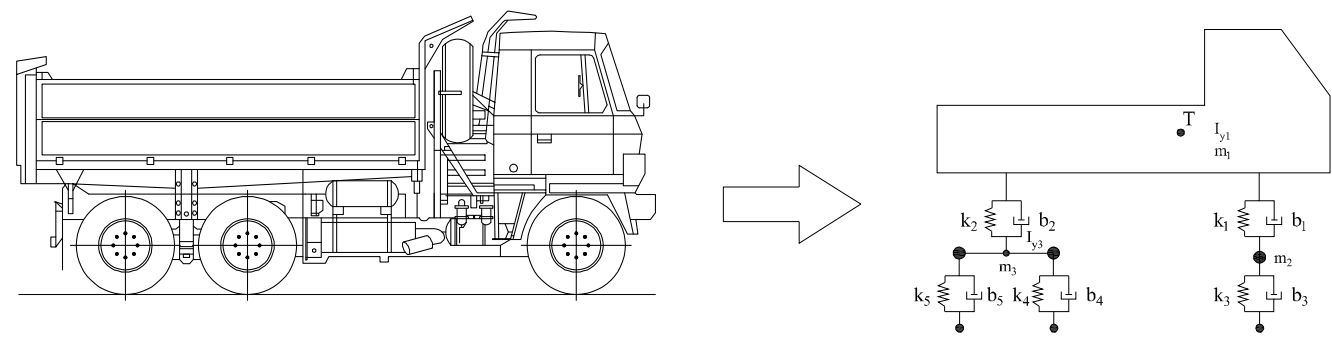

Fig. 1: Half-part model of the lorry Tatra 815.

The main characteristics of the half-part model are defined by three diagonal matrices - mass $\left\{m_{i}\right\}$, stiffness $\left\{k_{i}\right\}$, and damping $\left\{b_{i}\right\}$ matrices which contain experimentally measured values [3].

Matrices values for the lorry model have been determined:

$\left\{m_{i}\right\}_{D}=\left\{m_{1}, l_{y 1}, m_{2}, m_{3}, l_{y 3}\right\}_{D}=\{11475 ; 31149 ; 455 ; 1070 ; 466\}_{D}$,

$\left\{k_{i}\right\}_{D}=\left\{k_{1}, k_{2}, k_{3}, k_{4}, k_{5}\right\}_{D}=\{143716.5 ; 761256 ; 1275300 ; 2511360 ; 2511360\}_{D}$,

$\left\{b_{i}\right\}_{D}=\left\{b_{1}, b_{2}, b_{3}, b_{4}, b_{5}\right\}_{D}=\{19228,260197,2746,5494,5494\}_{D}$,

The natural frequencies have also been determined:

$\{f\}=\left\{f_{(1)} ; f_{(2)} ; f_{(3)} ; f_{(4)} ; f_{(5)}\right\}=\{1.13 ; 1.45 ; 8.89 ; 10.91 ; 11.71\}$

$\left[\mathrm{kg}, \mathrm{kg} \cdot \mathrm{m}^{2}\right]$,

$\left[\mathrm{N} \cdot \mathrm{m}^{-1}\right]$

$\left[\mathrm{kg} \cdot \mathrm{s}^{-1}\right]$.

$[\mathrm{Hz}]$.

\section{Numerical model of pavement}

Properties for the asphalt pavement were assumed in the calculations. The pavement configuration is shown in Fig. 2. Three upper layers (asphalt concrete) are considered as the beam with the height of $h=140 \mathrm{~mm}$ and the width $b=1.0 \mathrm{~m}$. The equivalent modulus of elasticity and cross section moment of inertia were calculated for these layers $E=4800 \mathrm{MPa}$ and $I=2.286667 \cdot 10^{-4} \mathrm{~m}^{4}$. Layers $4-6$ are introduced into calculation as Winkler foundation. Modulus of reaction $K\left[\mathrm{MN} / \mathrm{m}^{3}\right]$ was calculated in the program LAYMED [4]. The mass intensity of the beam $\mu[\mathrm{kg} / \mathrm{m}]$ is $310 \mathrm{~kg} / \mathrm{m}$. The damping is introduced using angular frequency $\omega_{b}=0.1 \mathrm{rad} / \mathrm{s}$.

\begin{tabular}{|ll|}
\hline SMA 11 & $40 \mathrm{~mm} E=5500 \mathrm{MPa} v=0.33$ \\
\hline AC 22 & $50 \mathrm{~mm} E=6000 \mathrm{MPa} v=0.30$ \\
\hline AC 22-L & $50 \mathrm{~mm} E=3050 \mathrm{MPa} v=0.33$ \\
\hline CBGM & $150 \mathrm{~mm} E=2000 \mathrm{MPa} v=0.22$ \\
\hline gravel $150 \mathrm{~mm} E=400 \mathrm{MPa} \quad v=0.30$ \\
\hline subgrade $\infty \quad E=60 \mathrm{MPa} \quad v=0.35$
\end{tabular}

Fig. 2: Multi-layered model of the ground (left) and beam on the springs simplification (right) [5].

\section{Description of numerical simulation}

One of the most important parts of the process of the numerical simulation is to create a proper computing model. For this case, the plane 2D model of the lorry Tatra 815 was selected as a representative vehicle (Fig. 1). The vehicle is moving on the pavement with specified material characteristics. Simulations S1 and S2 have been created using the computer software ADINA. It allows defining contact pairs between the elements of the vehicle and the ground to simulate the interaction between the pavement and the vehicle. The calculations have been executed with inputs of the lorry Tatra 815 as mentioned above.

The asphalt layers of the pavement have been modelled as a beam element of length $50 \mathrm{~m}$. The pavement is composed of surface for acceleration $(5 \mathrm{~m})$, surface for ride with constant speed $(40 \mathrm{~m})$ and surface for deceleration (5 m) (Fig. 3 and Fig. 4). Winkler elastic subbase is represented by 
the springs with specified stiffness defined by the modulus of reaction $K$. The ground is restrained by the boundary conditions and degrees of freedom that are necessary for the calculation.

An effective implicit time integration scheme was proposed for the finite element solution of nonlinear dynamic problems. Direct time integration is widely used in the finite element solutions of transient wave propagation. We consider the Bathe method and the Newmark trapezoidal rule [6].

\subsection{Numerical simulation S1}

Contact forces have been applied as a point loads acting in nodes (Fig. 3). Each force represents axle load acting on the pavement surface.

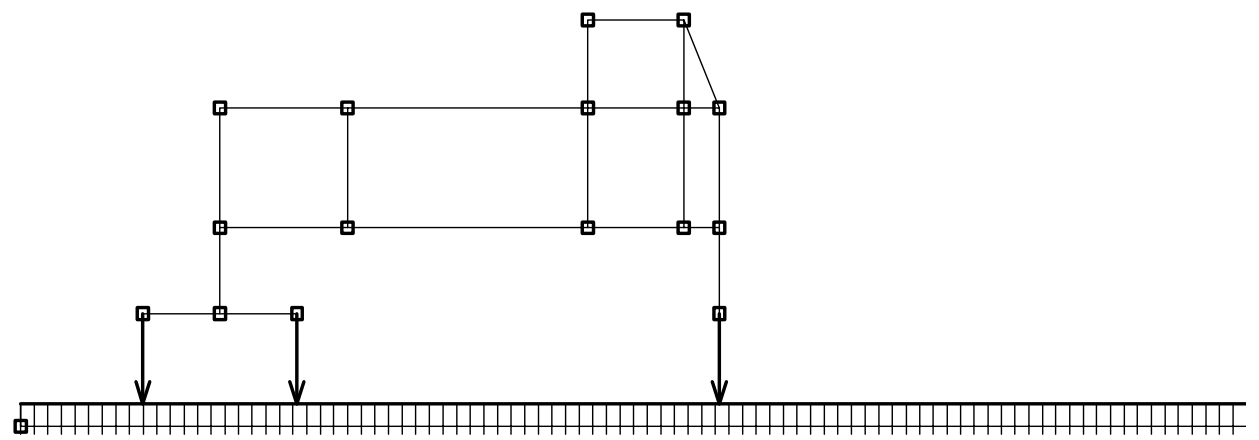

Fig. 3: Scheme of the computational model for the simulation S1.

\subsection{Numerical simulation $\mathrm{S} 2$}

Contact forces acting on the contact tyre areas are spread over these contact areas for this simulation. The tyre pressures are applied as a uniform distributed load (Fig. 4).

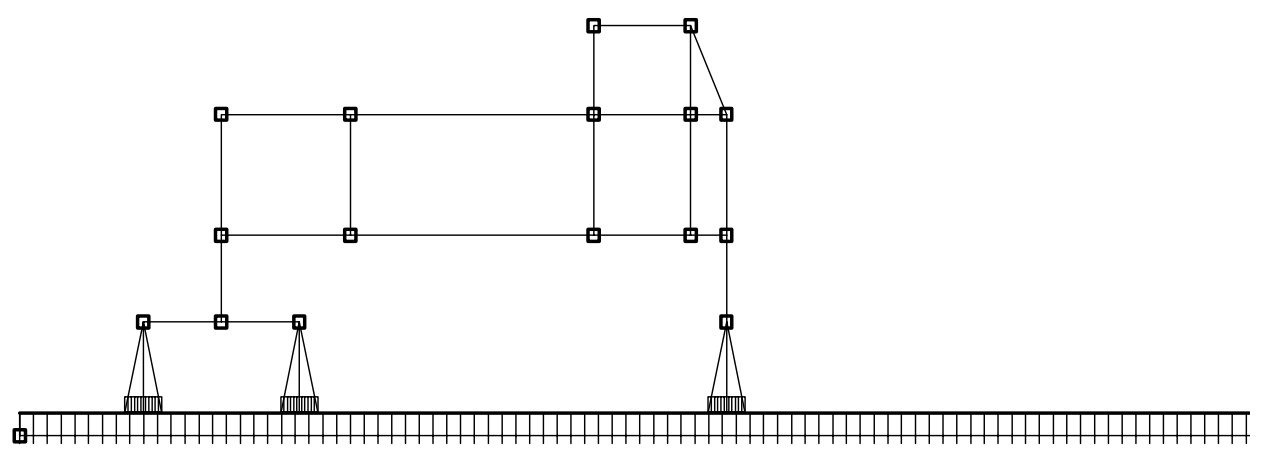

Fig. 4: Scheme of the computational model for the simulation S2.

\section{Description of the numerical procedure}

ADINA is commercial engineering simulation software that is used in industry and academia to solve structural, fluid and heat transfer, and electromagnetic problems. ADINA can also be used to solve multi-physics problems, including fluid-structure interactions and thermo-mechanical problems. ADINA is the acronym for Automatic Dynamic Incremental Nonlinear Analysis. The program consists of four core modules:

- ADINA Structures for linear and nonlinear analysis of solids and structures,

- ADINA Thermal for analysis of heat transfer in solids and field problems,

- ADINA CFD for analysis of compressible and incompressible flows, including heat transfer,

- ADINA EM for analysis of electromagnetic phenomena.

These modules can be used fully coupled together to solve multi-physics problems where the response of the system is affected by the interaction of several distinct physical fields (e.g. fluidstructure interaction, thermo-mechanical analysis, piezoelectric coupling, Joule heating, fluid flowmass transfer coupling, electromagnetic forces on fluids and structures, etc.) [7]. 


\subsection{Principles of numerical solver}

An effective implicit time integration scheme was proposed for the finite element solution of nonlinear dynamics problems. Direct time integration is widely used in the finite element solutions of transient wave propagation problems. However, accurate solution is difficult to obtain because of numerical dispersion and dissipation, resulting from period elongations and amplitude decays. In the solution of transient wave propagations, the errors from the spatial and temporal discretization appear together and affect each other. Analyses of these errors have led to the use of linear combinations of consistent and lumped mass matrices. Another approach is to reduce the solution errors by evaluating the mass and stiffness matrices using modified spatial integration rules. Such schemes can improve the accuracy of solutions of multi-dimensional wave propagation problems when using certain elements and meshes.

The dispersion errors resulting from the spatial discretization coupled with the temporal discretization are analysed. The Bathe method and the Newmark trapezoidal rule is considered. For this purpose, we handle the solution obtained for the scalar wave governed by:

$$
\frac{\partial^{2} u}{\partial t^{2}}-c_{0}^{2} \nabla^{2} u=0
$$

where $u$ is the field variable and $c_{0}$ is the wave velocity. Here, body forces are not considered since we focus on the dispersion associated with the propagations of disturbances due to initial conditions. The associated finite element discretization gives:

$$
M \ddot{U}+c_{0}^{2} K U=0,
$$

where $K$ and $M$ are the stiffness and mass matrices, and for element $(m)$ with volume $V^{(m)}$ :

$$
\begin{aligned}
& M^{(m)}=\int_{V^{(m)}} H^{(m)^{T}} d V^{(m)}, \\
& K^{(m)}=\int_{V^{(m)}}\left(\nabla H^{(m)}\right)^{T}\left(\nabla H^{(m)}\right) d V^{(m)} .
\end{aligned}
$$

Here, $H^{(m)}$ and $U$ are the element interpolation matrix and the nodal values of the solution, respectively. The matrices $M$ and $K$ in Eq. (3) are obtained by the usual summation process.

In the Bathe method, the following relations are employed:

$$
\begin{aligned}
& { }^{t+\Delta t / 2} \dot{U}={ }^{t} \dot{U}+\left[\frac{\Delta t}{4}\right]\left({ }^{t} \ddot{U}+{ }^{t+\Delta t / 2} \ddot{U}\right), \\
& { }^{t+\Delta t / 2} U={ }^{t} U+\left[\frac{\Delta t}{4}\right]\left({ }^{t} \dot{U}+{ }^{t+\Delta t / 2} \dot{U}\right), \\
& { }^{t+\Delta t} \dot{U}=\frac{1}{\Delta t}{ }^{t} U-\left[\frac{4}{\Delta t}\right]{ }^{t+\Delta t / 2} U+\frac{3}{\Delta t}{ }^{t+\Delta t} U, \\
& { }^{t+\Delta t} \ddot{U}=\frac{1}{\Delta t}{ }^{t} \dot{U}-\left[\frac{4}{\Delta t}\right]{ }^{t+\Delta t / 2} \dot{U}+\frac{3}{\Delta t}{ }^{t+\Delta t} \dot{U} .
\end{aligned}
$$

Using Eq. (3) at times $t, t+\Delta t / 2$ and $t+\Delta t$, where $t$ denotes the current time and $\Delta t$ the time step, with Eqs. (6) - (9), we obtain a linear multistep form of the Bathe method:

$$
\left(72 M+8 c_{0}^{2} \Delta t^{2} K\right)^{t+\Delta t} U+\left(-144 M+5 c_{0}^{2} \Delta t^{2} K\right)^{t+\frac{\Delta t}{2}} U+\left(72 M+5 c_{0}^{2} \Delta t^{k} K\right)^{t} U=0 .
$$

Using the definition of the $C F L$ number, $C F L=\frac{c_{0} A t}{h}$, where $h$ is the characteristic length of a finite element (or used fundamental length), Eq. (10) becomes: 


$$
(72 M+8 \gamma K)^{t+\Delta t} U+(-144 M+5 \gamma K)^{t+\frac{\Delta t}{2}} U+(72 M+5 \gamma K)^{t} U=0,
$$

where $\gamma=C F L^{2} h^{2}$, [5].

\section{Results and discussion}

Following charts represent the outputs of the simulations S1 (point load) and S2 (distributed load) for vertical accelerations, velocities and displacements. Results are presented for quantities in vertical axis and have been obtained in 2D simulations in $\mathrm{XZ}$ plane.

Charts show minor differences between results of both simulations with the exception of the vertical accelerations $a_{3}$. Distributed load (S2) causes significantly larger values of the vertical accelerations. Differences are up to $300 \%$ for the peak values corresponding to the axle passes. Differences in the values of the velocities $v_{3}$ and displacements $u_{3}$ between simulations reached 12 to $22 \%$ and 5.1 to $7.3 \%$ respectively.

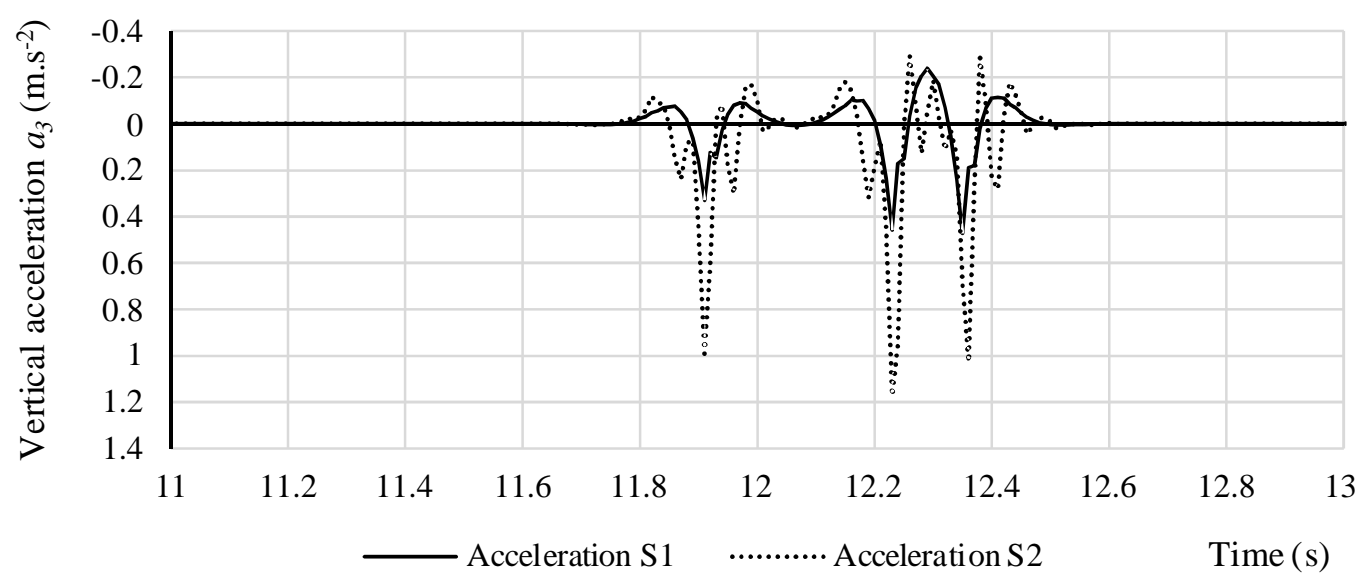

Fig. 5: Propagation of vertical accelerations for simulations S1 and S2.

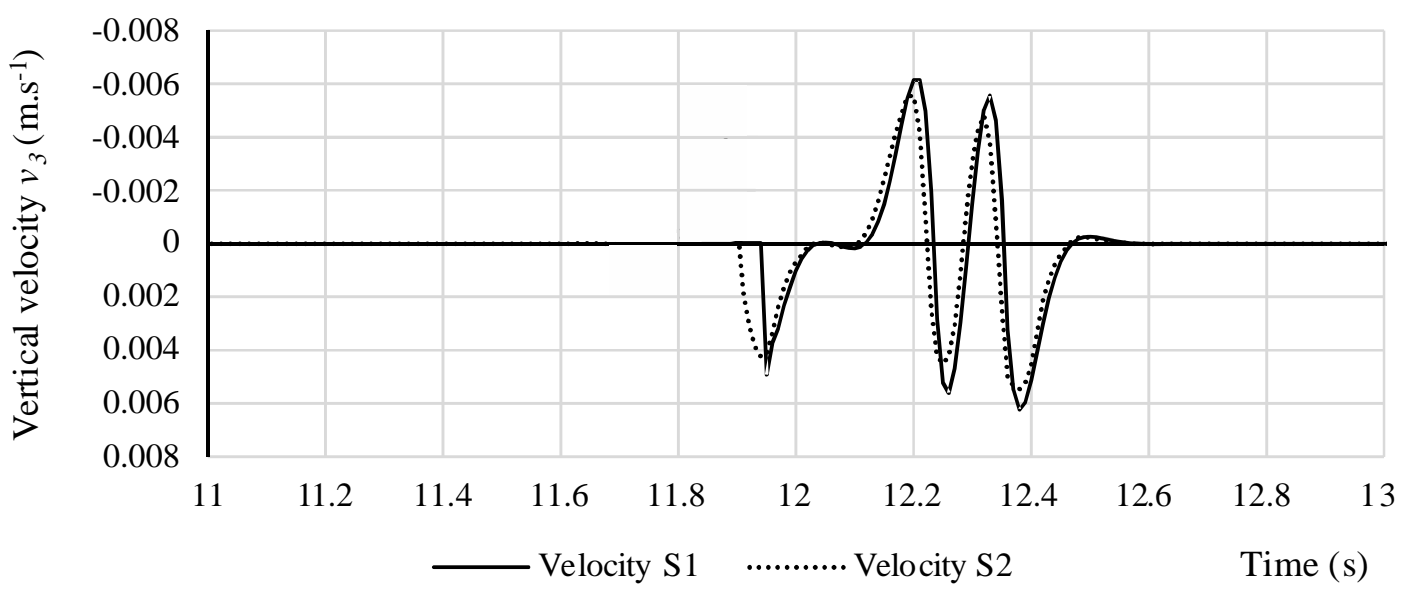

Fig. 6: Propagation of vertical velocities for simulations S1 and S2. 


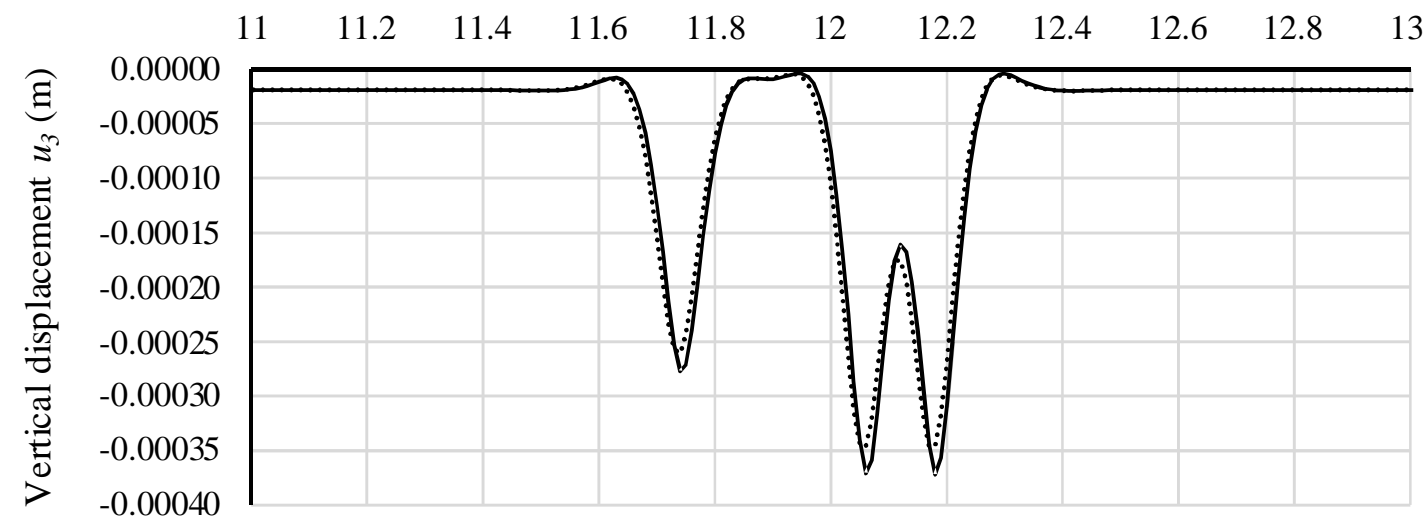

— Displacement S1 …...... Displacement S2 Time (s)

Fig. 7: Propagation of vertical displacements for simulations S1 and S2.

\section{Conclusions}

The article demonstrates that the using of FEM methods can give useful results of numerical analysis of this phenomenon. Two approaches of load application are presented in this paper. It has been used point or distributed load, for simulation wheel pressure on the pavement needs to be considered. Depending on the investigated quantities the outputs bring differences that will be verified by the experimental measurements in further studies. Distributed load show of larger deviations was compared to the point load simulation, especially for the vertical accelerations. Quantities such as accelerations and velocities are crucial for the evaluation of the influence of the traffic load on the surrounding building structures in terms of the technical seismicity standards. On the contrary, propagation of the vertical displacements can be considered equal for both simulations.

The distributed load better describes the real effect of the tyre on the pavement and nonuniform distribution of the tyre pressure will be investigated in further research using experiment and numerical modelling.

\section{Acknowledgement}

This paper was supported by the Grant National Agency VEGA of the Slovak Republic (grant No. $1 / 0005 / 16)$.

\section{References}

[1] FRÝBA, L.: Vibration of Solids and Structures under Moving Loads. ACADEMIA, Praha, Nordhoff International Publishing, Groningen, 1972.

[2] MARTINICKÁ, I.: Calculation of Natural Frequencies and Vibration Shapes its own Computational Models of Vehicles. In: Land Communications and Tracks, 6 (1 - 2), 2010, p. $41-50$.

[3] DANIEL, L. - VALAŠKOVÁ, V. - KORTIŠ, J.: Numerical Simulation of Moving Vehicle across the Obstacle. In: Civil and Environmental Engineering, Vol. 10 (2), 2014, p. 108 - 112.

[4] NOVOTNÝ, B. - HANUŠKA, A.: Theory of Layered Half-space (in Slovak), first ed., VEDA, SAV, Bratislava, 1983.

[5] LAJČÁKOVÁ, G. - MELCER, J.: Computing models of concrete pavements. In: Modelování v mechanice 2012. Ostrava, VŠB - Technical University, 2012, p. 13 - 15.

[6] GUNWOO, Y. N. - SEOUNGHYUN, H. - BATHE, K. J.: Performance of an Implicit Time Integration Scheme in the Analysis of Wave Propagations. In: Computers and Structures, 123, 2013, p. $93-105$.

[7] ADINA R \& D.: Theory and Modeling Guide. Volume I: ADINA. ADINA R \& D, Inc., Watertown, MA, USA, 2012. 